\title{
THE PRINCIPLE OF COMBINED PREOPERATIVE DIAGNOSIS OF THYROID TUMORS
}

DOI: 10.36740/WLek202103127

\author{
Olga I. Zalyubovska', Nadiia 0. Hladkykh', Petro 0. Gritsenko² \\ 'KHARKIV NATIONAL MEDICAL UNIVERSITY, KHARKIV, UKRAINE \\ 2STATE INSTITUTION «DNIPROPETROVSK MEDICAL ACADEMY OF THE MINISTRY OF HEALTH OF UKRAINE», DNIPRO, UKRAINE
}

\begin{abstract}
The aim of the research is to increase the effectiveness of preoperative diagnosis of patients with thyroid tumors and to assess the use of cancer-embryonic antigen and immunocytochemical research.

Materials and methods: Patients were interviewed about their complaints and lifestyle; performed ultrasound with fine-needle aspiration, determination of the level of cancer-embryonic antigen (CEA), cytological and immunocytochemical researches.

Results: The Benign process in the thyroid gland is low serum REA (less than $0.95 \mathrm{ng} / \mathrm{ml}$ ), poor expression of thyroglobulin (77.8\%), negative reaction with TTF-1 (100\%) and cytokeratin-19 (55.6\%). Differential-prognostic markers of thyroid neoplasms with risk of malignancy include increased serum REA ( $0.95 \mathrm{ng} / \mathrm{ml}$ and above), the presence of a moderate reaction with antibodies to thyroglobulin (80.0\%), a positive reaction — to TTF-1 (100.0\%) and E-cadherin (90.0\%), with moderate or strong expression of cytokeratin-19 (90.0\%). Statistically significant markers of malignant thyroid disease were determined: the presence of harmful factors at work (45.5\%), smoking (27.3\%), elevated serum REA $(0.95 \mathrm{ng} / \mathrm{ml}$ and above), the presence of strong cytoplasmic expression of thyroglobulin (63.6\%), moderate or strong expression of TTF-1 (90.9\%) and cytokeratin-19 (81.8\%). Conclusions: The most appropriate and practically significant for preoperative diagnosis of thyroid tumors is a set of several diagnostic methods, which are carried out in one hospital - ultrasound with fine-needle aspiration, cytomorphological, and immunocytochemical and REA levels in a primary screening.
\end{abstract}

KEY WORDS: thyroid gland, nodular diseases of the thyroid gland, carcinoma, diagnosis, fine-needle aspiration puncture biopsy

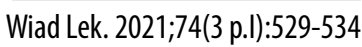

\section{INTRODUCTION}

Today thyroid disease is taking one of the leading places among endocrine pathology in terms of overall morbidity and prevalence in the world. Due to the environmental situation in Ukraine, this problem is attracting more and more attention every year. This indicator varies significantly in different regions of the country and depends on the influence of environmental factors like stress, iodine deficiency, lifestyle, malnutrition, micronutrient deficiencies, and comorbidity. In general, diseases of the endocrine glands and, in particular, pathology of the thyroid gland cause great socioeconomic damage which is determined by the cost of medical care and social security (due to disability, premature death) $[1,2,3]$.

Mass surveys of the population after the accident revealed a high prevalence of thyroid enlargement (in $20-40 \%$ of those who were surveyed) $[4,5]$. O.B. Kaminsky and his co-authors (2016) conducted a retrospective analysis of data and found that the incidence of thyroid pathology among all victims of the Chernobyl accident was $40.3 \%$, among the participants in the aftermath of the accident $-35.4 \%$, among those who evacuated from the exclusion zone $-27.2 \%$, residents of radiation-contaminated areas $-28.6 \%$, which is much more $(\mathrm{p}<0.0001)$ than the general population $(3.9 \%)$ of Ukraine [6]. According to the National Cancer Registry of Ukraine, 137,266 new cases of malignant neoplasms (MN) were registered in 2017; the total incidence of $\mathrm{ZN}$ was 381.4 per 100 thousand of the population, including 392.5 for men and 371.7 for women. Thyroid cancer is more often diagnosed among malignant tumors of the endocrine organs and in the overall structure of cancer is 1-3\%. In Ukraine, the prevalence of thyroid cancer was 8.2 per 100 thousand of the population in 2018 and 8.3 per 100 thousand of the population in 2019. The incidence rate per 100 thousand of the population in Dnipropetrovsk region was 6.7, of which 3.1 - among men and 9.8 - among women [7]. The share of thyroid cancer is $0.5-1.5 \%$ in the structure of all malignant neoplasms depending on age, gender, radiation exposure, hereditary history and other factors. According to world data, the incidence of thyroid cancer is 20-80 cases per 100 thousand of the population per year, mortality -5 per 1 million of the population per year $[8$, $9,10]$. However, there are no unified clinical protocols in endocrinology for the provision of medical care to adults with thyroid pathology in Ukraine. Therefore, it is important to supplement modern approaches to the diagnosis of such diseases, analysis of scientific and practical aspects 
of treatment and monitoring of thyroid nodules based on current international guidelines of the American Thyroid Association for adult patients with thyroid nodules and differentiated thyroid cancer, year 2015; joint consensus of the American Association of Clinical Endocrinologists, the Italian Association of Clinical Endocrinologists, the European Thyroid Association, year 2010, with taking into the account of evidence-based medicine [11].

\section{THE AIM}

The aim of the research is to increase the effectiveness of preoperative diagnosis of patients with thyroid tumors and to assess the use of cancer-embryonic antigen and immunocytochemical research.

\section{MATERIALS AND METHODS}

During the the research work the results of diagnostics of 60 patients with thyroid neoplasms aged 21 to 83 years (mean age $54.6 \pm 1.9$ years) who underwent fine-needle aspiration puncture biopsy were obtained in the polyclinic Communal Institution "Dnipropetrovsk Regional Clinical Hospital named after I.I. Mechnykov".

Patients were divided into three groups according to the Bethesda System (BSRTC) classification category. The 1st group included 18 patients of category II BSRTC (Benign, benign lesions), of which $88.9 \%$ were women and $11.1 \%$ were men and the mean age was $46.6 \pm 3.7$ years. Group 2 included 20 patients with category V BSRTC (Suspicious for Malignancy - SFM, suspected malignancy), female $(100 \%)$ and mean age $58.7 \pm 3.1$ years. In addition, other 22 patients with category VI BSRTC (malignant tumor) formed the 3rd group, of which $90.9 \%$ were women and $9.1 \%$ were men, the mean age was $57.4 \pm 2.4$ years. The research included patients with the first established TR- 4 category of thyroid nodule on the TI-RADS scale (4-6 points, suspected of malignant thyroid changes).

Patients were interviewed about their complaints, history, lifestyle and negative health factors; quality of life assessment MOS SF-36 (Medical Outcomes Study Short Form Health Status Survey), ultrasound on the device Toshiba SSA-580A with electronic linear sensors with a frequency of 9-12 MHz and a scanning surface length of $6 \mathrm{~cm}$, fine-needle aspiration $23 \mathrm{G}(0.6 \times 25 \mathrm{~mm})$, determination of the level of cancer-embryonic antigen (CEA) on the analyzer Cobas e-411 (Roche Diagnostics GmbH), cytological and immunocytochemical researches.

Informative were considered drugs from at least 6 groups of thyroid cells, at least ten follicular cells each (preferably in one drug). The puncture material on the slide was airdried and fixed with methanol for 5 minutes, staining for 30 minutes by the Romanovsky method. The results of the cytological examination were evaluated by the Bethesda System (BSRTC) with a standard cytological protocol. Immunocytochemical researches were conducted at points fixed with methanol and stained according to Romanovsky method by restoring the activity of antigenic determinants.
An indirect immunoperoxidase method using mouse monoclonal antibodies was used (Dako Cytomation, Denmark). Antibodies against mouse g-globulins labeled with horseradish peroxidase (Dako Cytomation, Denmark) were used as secondary. Control tests were used to assess the adequacy of the methodological procedure. Evaluation of the specificity of the interaction of antibodies with tissue antigens was performed using positive and negative controls. The results were analyzed by determining the number of positive $(+)$ cells using an Axiostar plus microscope (Carl Zeiss, Germany) at a magnification of 320 times, and evaluated using the classical H-Score method. Statistical processing of the results was performed using the methods of parametric and nonparametric statistics, implemented in the application packages MDCalc statistical software and Microsoft Excel 2019 (Microsoft). The assessment of the conformity of the distribution of quantitative values of the data to the normal law was performed using the Shapiro-Wilk test. Under the conditions of the normal distribution law, we used the arithmetic mean and it's standard error $(M \pm m)$, one-way analysis of variance ANOVA (F) with a posteriori comparison of groups with each other by Tukey (HSD); in other cases - median (Me), interquartile range (25-75\%), nonparametric analysis of Kruskal-Wallis ANOVA (H) followed by Multiple Comparisons (MS). Comparison of relative indicators were conducted according to the Pearson Chi-square test (c2) and the two-sided Fisher's Exact Test (FET). The correlation between the factors was determined by criterion $\mathrm{c} 2$ and Spearman's rank correlation coefficients (r). To assess the discriminant significance of the REA indicator for predicting the malignancy of the process, an ROC analysis was conducted with the calculation of the area under the ROC curve (AUC) and operational characteristics (sensitivity, specificity) with a $95 \%$ confidence interval $(95 \% \mathrm{CI})$. The level of $p<0.05(5 \%)$ was considered statistically significant.

\section{RESULTS}

A comparative analysis of the studied indicators (Table I) showed that the selected groups probably did not differ in the gender of patients $\left(\chi^{2}=2.21, \mathrm{p}>0.05\right)$, body mass index $(\mathrm{F}=$ $0.25, \mathrm{p}>0.05)$, the size and area of the tumor according to ultrasound $(\mathrm{H}=2.30, \mathrm{p}>0.05$ and $\mathrm{H}=1.92, \mathrm{p}>0.05$, respectively). At the same time, patients of the 1st group were younger in age than (when) compared with patients of other groups ( $p<0.05$ according to the HSD criterion). It should be noted that more than half of patients in all research groups were overweight or had grade I-II of obesity (WHO, 1997) - 55.6\%; 50.0\%; 72.7\%, respectively, in the 1st, 2nd and 3rd groups.

According to the results of the questionnaire (Table II), hereditary burden of thyroid disease was noted by $10 \mathrm{pa}-$ tients $(16.7 \%)$ from the 1 st $(\mathrm{n}=4-22.2 \%)$ and $2 \mathrm{nd}(\mathrm{n}=$ $6-30.0) \%$ ) group, while in the 3rd group there were no such kind of cases $(p<0,05)$. One in five patients in the research groups was in areas of high radiation exposure, with no significant differences between the groups $\left(\chi^{2}=\right.$ $0.10, p>0.05)$. However, almost half of the patients of the 
Table I. General characteristics of patients and thyroid tumors

\begin{tabular}{|c|c|c|c|c|}
\hline \multirow[b]{2}{*}{ Indicator } & \multicolumn{3}{|c|}{ Research groups } & \multirow{2}{*}{$\begin{array}{c}\text { General difference } \\
\text { between the } \\
\text { groups }\end{array}$} \\
\hline & $\begin{array}{l}\text { Group } 1 \\
(n=18)\end{array}$ & $\begin{array}{c}\text { Group } 2 \\
(n=20)\end{array}$ & $\begin{array}{l}\text { Group } 3 \\
(n=22)\end{array}$ & \\
\hline $\begin{array}{c}\text { Gender, \% } \\
\text { ffemale/ male }\end{array}$ & $88,9 / 11,1$ & $100 / 0$ & $90,9 / 9,1$ & $x^{2}=2,21, p=0,331$ \\
\hline Age, years, $M \pm m$ & $46,6 \pm 3,7$ & $58,7 \pm 3,1^{*}$ & $57,4 \pm 2,4^{*}$ & $F=4,51, p=0,015$ \\
\hline $\mathrm{BMI}, \mathrm{kg} / \mathrm{m}^{2}, \mathrm{M} \pm \mathrm{m}$ & $28,7 \pm 1,3$ & $27,5 \pm 1,4$ & $27,8 \pm 0,8$ & $F=0,25, p=0,777$ \\
\hline $\begin{array}{l}\text { Max diameter of formation, } \mathrm{mm} \text {, } \\
\text { Me }(25-75 \%)\end{array}$ & $\begin{array}{c}15,0 \\
(13,0-17,0)\end{array}$ & $\begin{array}{c}11,0 \\
(10,0-20,0)\end{array}$ & $\begin{array}{c}12,0 \\
(10,0-27,0)\end{array}$ & $\begin{array}{l}H=2,30 \\
p=0,316\end{array}$ \\
\hline Area of formation, $\mathrm{mm}^{2}, \mathrm{Me}(25-75 \%)$ & $\begin{array}{c}135,0 \\
(112,0-225,0)\end{array}$ & $\begin{array}{c}106,0 \\
(60,0-312,0)\end{array}$ & $\begin{array}{c}120,0 \\
(70,0-513,0)\end{array}$ & $\begin{array}{l}H=1,92, \\
p=0,383\end{array}$ \\
\hline
\end{tabular}

Note. ${ }^{*}-p<0.05$ compared to group 1 (by HSD criterion)

Table II. Frequency of detection of risk factors and clinical signs of thyroid tumors of patients of research groups (abs. / \%)

\begin{tabular}{|c|c|c|c|c|}
\hline \multirow{2}{*}{ Indicator } & \multicolumn{3}{|c|}{ Research groups } & \multirow{2}{*}{$\begin{array}{l}\text { General difference } \\
\text { between the groups }\end{array}$} \\
\hline & Group $1(n=18)$ & Group $2(n=20)$ & Group $3(n=22)$ & \\
\hline Hereditary (genetic) factor & $4 / 22,2^{*}$ & $6 / 30,0^{*}$ & $0 / 0$ & $\begin{array}{l}x^{2}=7,36 \\
p=0,025\end{array}$ \\
\hline Harmful factors at work & $4 / 22,2$ & $2 / 10,0^{*}$ & $10 / 45,5$ & $\begin{array}{l}x^{2}=6,99 \\
p=0,030\end{array}$ \\
\hline Smoking & $0 / 0^{*}$ & $0 / 0^{*}$ & $6 / 27,3$ & $\begin{array}{l}x^{2}=11,52 \\
p=0,003\end{array}$ \\
\hline $\begin{array}{l}\text { Staying in areas of high radiation } \\
\text { exposure }\end{array}$ & $4 / 22,2$ & $4 / 20,0$ & $4 / 18,2$ & $\begin{array}{l}x^{2}=0,10 \\
p=0,951\end{array}$ \\
\hline The pressure in the neck & $8 / 44,4$ & $6 / 30,0$ & $6 / 27,3$ & $\begin{array}{l}x^{2}=1,46 \\
p=0,481\end{array}$ \\
\hline Hoarseness & $2 / 11,1$ & $6 / 30,0$ & $4 / 18,2$ & $\begin{array}{l}x^{2}=2,18 \\
p=0,335\end{array}$ \\
\hline Impaired swallowing & $2 / 11,1$ & $6 / 30,0$ & $2 / 9,1$ & $\begin{array}{l}x^{2}=3,87 \\
p=0,145\end{array}$ \\
\hline Delayed passage of food & $6 / 33,3$ & $2 / 10,0$ & $4 / 18,2$ & $\begin{array}{l}x^{2}=3,30 \\
p=0,192\end{array}$ \\
\hline
\end{tabular}

Note. $^{*}-p<0.05$ compared to group 3 (by FET criterion)

Table III. Level of cancer-embryonic antigen (CEA, ng / ml) of patients of the research groups

\begin{tabular}{|c|c|c|c|c|}
\hline \multirow[b]{2}{*}{ Research group } & \multicolumn{3}{|c|}{ Statistical characteristics } & \multirow[b]{2}{*}{ Reference values } \\
\hline & Min - max & $\begin{array}{c}M e \\
(25-75 \%)\end{array}$ & $\begin{array}{c}\text { General difference } \\
\text { between the groups }\end{array}$ & \\
\hline $\begin{array}{l}\text { Group } 1 \\
(n=18)\end{array}$ & $0,20-3,31$ & $\begin{array}{c}0,90 \\
(0,53-1,92)\end{array}$ & \multirow{3}{*}{$\begin{array}{l}H=9,01 \\
p=0,011\end{array}$} & $\begin{array}{c}\text { 1. All subjects: } \\
20-69 \text { years to } 4,7 \\
40-69 \text { to } 5,2\end{array}$ \\
\hline $\begin{array}{c}\text { Group } 2 \\
(n=20)\end{array}$ & $0,84-3,70$ & $\begin{array}{c}2,01 * \\
(1,36-2,23) \\
\end{array}$ & & $\begin{array}{l}\text { 2. Do not smoke or have smoked in the past: } \\
\qquad \begin{array}{l}20-69 \text { years to } 3,8 \\
40-69 \text { years to } 5,0\end{array}\end{array}$ \\
\hline $\begin{array}{l}\text { Group } 3 \\
(n=22)\end{array}$ & $0,50-85,83$ & $\begin{array}{c}2,05 * \\
(1,17-3,99)\end{array}$ & & $\begin{array}{l}\text { 3. Smoke now: } \\
20-69 \text { years to } 5,5 \\
40-69 \text { years to } 6,5\end{array}$ \\
\hline
\end{tabular}

Note. ${ }^{*}-p<0.05$ compared to the 1 st group (according to the MC criterion)

3rd group (45.5\%) had harmful factors at work against $10.0 \%$ of the patients in the $2 \mathrm{nd}(\mathrm{p}<0.05)$ and $22.2 \%$ in the 1st group ( $p>0,05)$. Smoking was observed only among patients of group $3(27.3 \%)$ at $p<0.05$ compared with other groups. Thus, the analysis of anamnestic data showed that the most characteristic risk factors for the development of malignant processes in the thyroid gland are the presence of harmful factors at work and smoking.

Analysis of patient complaints showed the absence of pathognomonic clinical signs characteristic of thyroid 


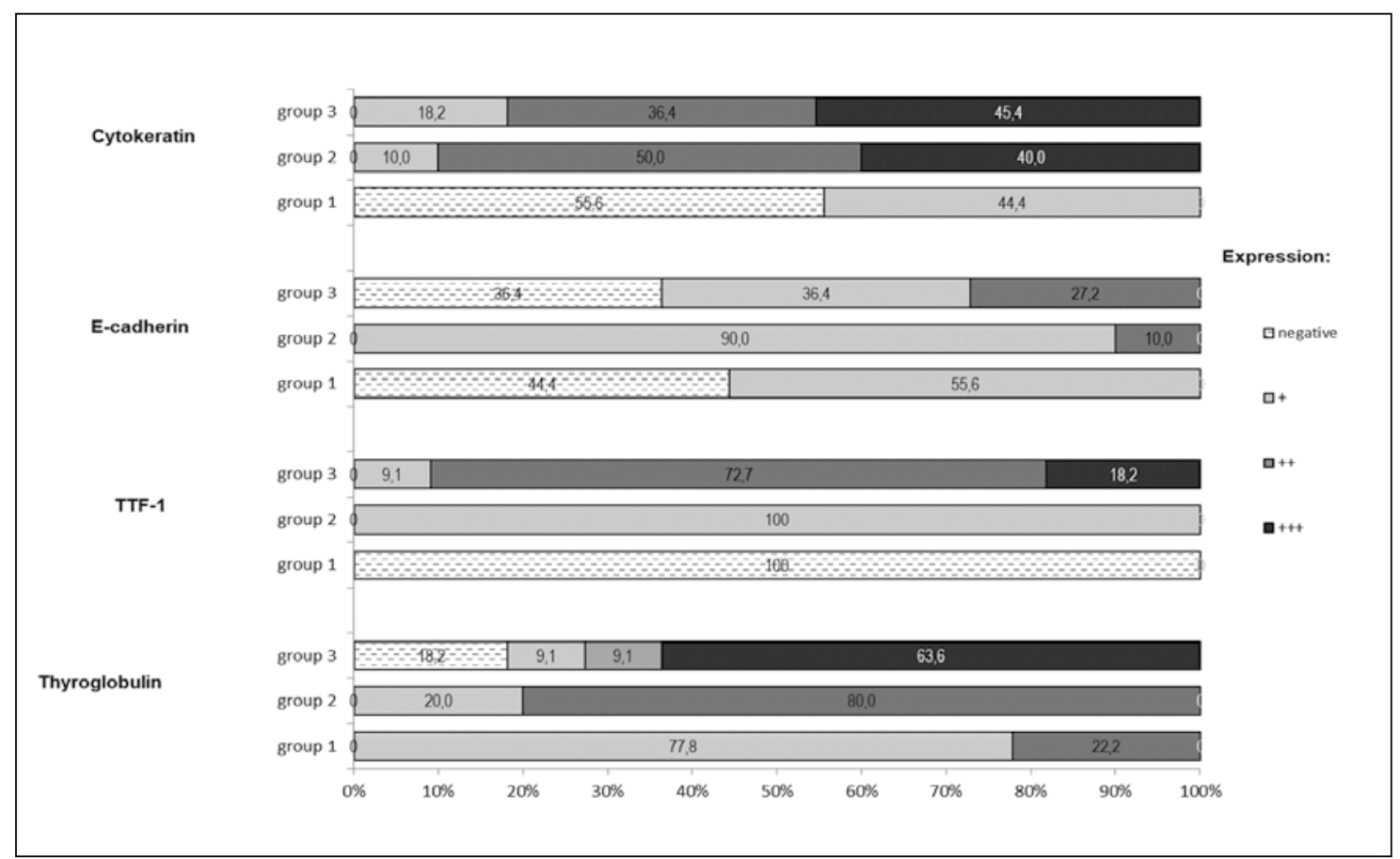

Fig. 1. The frequency of expression of thyroglobulin, TTF-1, E-cadherin and cytokeratin-19 of different intensity in the cells of thyroid tumors with different classification category according to BSRTC

tumors with different classification category according to BSRTC (Table II). Pressure in the neck was felt by about a third of patients $-20(33.3 \%)$, hoarseness was noted by 12 (20.0\%), swallowing disorders - 10 (16.7\%), delayed passage of food - $12(20.0)$. \%) patients, without probable differences between groups ( $\mathrm{p}>0.05)$. At the same time, according to the correlation analysis, a direct correlation was established between the delay in the passage of food and the size of the tumor $-\mathrm{r}=0.34 ; \mathrm{p}<0.01$.

The research of the level of cancer-embryonic antigen (CEA) in the serum of thematic patients showed the presence of a direct correlation between the indicators depending on the degree of malignancy of the process in the thyroid gland $-\mathrm{r}=0.33 ; \mathrm{p}<0.01$. In benign thyroid disease (group 1), the level of CEA of all patients did not exceed the reference range, ranged from 0.20 to $3.31 \mathrm{ng} / \mathrm{ml}$ and averaged $0.90(0.53-1.92) \mathrm{ng} / \mathrm{ml}$ (Table III). Patients with category B BSRTC (group 2), the rate ranged from 0.84 to $3.70 \mathrm{ng} / \mathrm{ml}$, also without exceeding the reference values. However, the median index was 2.2 times higher than in the 1st group ( $<<0.05)$. In $18.2 \%$ of patients in group $3(n=4)$, who were confirmed in the postoperative stage of metastatic lymph node involvement, the level of PEA was above normal. The mean for this cohort of patients was 2.05 (1.17-3.99) $\mathrm{ng} / \mathrm{ml}$, probably exceeded the corresponding value of patients with a benign process by 2.3 times $(\mathrm{p}<0.05)$, but did not differ statistically from indicator of the 2 nd group ( $p>0.05)$. Therefore, the serum level of REA can serve as a differential diagnostic criterion and indicate a potentially malignant origin of the tumor. According to ROC-analysis, it is established that a high probability of malignant transformation of the thyroid lymph node is predicted by increasing serum REA to 0.95 $\mathrm{ng} / \mathrm{ml}$ and above - the area under the ROC curve AUC 0.746 (95\% CI $0.617-0.850)$ at $\mathrm{p}<0.001$, which provides the sensitivity of the criterion 85.7 (95\% CI 75.1-96.3)\%, specificity - 66.7 (95\% CI 44.9-88.4)\%.

Comparative analysis of immunocytochemical data of patients with thyroid tumors revealed the correlation between the expression of thyroglobulin, thyroid transcription factor-1 (TTF-1), E-cadherin and cytokeratin-19 with the potential for tumor malignancy for pragmatic aspect of preoperative diagnosis.

It was found that patients with BSRTC-2 (group 1) had a weak expression of thyroglobulin (thyroid hormone) in $77.8 \%(\mathrm{n}=14)$ cases and moderate in $22.2 \%(\mathrm{n}=4)$. In the 2nd group of patients with V category BSRTC there was an increase in the intensity of the reaction with antibodies to thyroglobulin: only in $20.0 \%$ of cases $(n=4)$ the expression was weak, and in $80.0 \%(\mathrm{n}=16)$ - moderate $(\mathrm{p}<0.001$ compared with group 1). With metastatic thyroid disease (group 3), high thyroglobulin expression was observed in $63.6 \%(\mathrm{n}=14)$ of patients, moderate - in 9.1\% $(n=2)$, weak - in 9.1\% $(n=2)$, a negative result was obtained in $18.2 \%(\mathrm{n}=4)$ cases ( $p<0.001$ against the data in the 1 st and 2 nd groups) (Fig. 1 ). Correlation analysis confirms a direct correlation between the frequency of increased immunogenic expression of thyroglobulin and the potential for malignancy of the thyroid gland $-\chi^{2}=62.53 ; \mathrm{r}=0.49 ; \mathrm{p}<0,001$, which emphasizes the prognostic value of this marker for the identification of malignant processes in the preoperative stage.

The research of the proliferative activity of thyroid tissue based on the expression of TTF-1 protein showed it's high differential prognostic significance for assessing the risk of 
malignant process in the thyroid gland $-\chi 2=109.6 ; \mathrm{r}=0.96$; $\mathrm{p}<0.001$. Thus, in the benign process in all cases $(100 \%)$ the negative status of TTF-1 expression was established, in the case of suspected tumor malignancy - a weak reaction $(+)$ in $100 \%$ of patients $(\mathrm{p}<0.001)$, in metastatic lesions - in $18.2 \%$ cases of strong expression $(+++)$, in $72.7 \%$ - moderate $(++)$, in $9.1 \%$ - weak ( $\mathrm{p}<0.001$ compared to previous groups).

The research of the reaction of E-cadherin, which functions as an antitumor suppressor (anti-oncogene), in the studied samples of thyroid tumors showed mixed results (Fig. 1). In the benign nature of the thyroid tumor (group 1), suppression of E-cadherin expression was determined: in $44.4 \%$ of cases, the expression was absent, in $55.6 \%$ - a weak reaction was noted. The presence of a positive reaction of E-cadherin was noted in all biopsies (100\%) with suspected malignancy (group 2); including weak expression was observed in $90.0 \%$ of cases, moderate reaction - in $10.0 \%$ ( $p<0.001$ compared with benign lesions). At the same time, there is no clear link between E-cadherin expression and neoplasia. Negative expression occurred in $36.4 \%$ of cases of metastatic thyroid disease, weak reaction - in $36.4 \%$, moderate reaction - in $27.2 \%$ ( $p=0.053$ and $\mathrm{p}=0.001$ compared with the 1 st and 2 nd groups in accordance). This partially satisfies the requirements of timely preoperative diagnosis.

In contrast to the previous marker, the expression of cytokeratin-19 with varying degrees of intensity of cytoplasmic staining of tumor cells was determined in all studied neoplasms of V and VI category on the BSRTC scale. Strong expression of cytokeratin-19 was observed in $40.0 \%$ of cases with BSRTC- 5 and $45.4 \%$ with BSRTC- 6 , moderate - in $50.0 \%$ and $36.4 \%$ of cases, respectively, weak - in $10.0 \%$ and $18.2 \%$, without significant differences between groups ( $p>0.05)$. At the same time, in the benign process in $55.6 \%$ of cases there was no reaction of cytokeratin-19, and in $44.4 \%$ - weak expression ( $p<0.001$ in comparison with the 2 nd and 3 rd groups). Therefore, on the puncture material with the thyroid gland cytokeratin-19 is a promising marker for the identification of malignant processes.

\section{DISCUSSION}

The relevance of this study is because the pathology of the thyroid gland is one of the main places among endocrine pathology in terms of overall morbidity [1]. It is obvious that predicting an increase in the number of cases of thyroid cancer for the next 30 years reflects the problem of diagnosis $[4,5]$. In modern international protocols of endocrinology, there are no data on the use of the above set of markers in the preoperative stage of diagnosis [11]. Cytological examination of thyroid tumors is considered a minimally invasive procedure, but to obtain adequate material is not always possible and depends on many factors. Based on this, the introduction of immunocytochemical and immunochemiluminescent analysis was proposed.

The reliable results of these methods obtained by us testify to the expediency of including them in the basic set of diagnostic procedures used for dynamic monitoring of patients. Given the fact that after the analysis of pathomorphological study it was concluded that the sensitivity of the level of CEA is high only in the serum of patients with poorly differentiated carcinoma. Use as an auxiliary marker for predicting the course of the tumor process is appropriate. Only one-time application of these diagnostic stages can bring closer the earlier appointment of adequate treatment and reduce the cost of expensive procedures.

\section{CONCLUSIONS}

Our comprehensive researches of patients with thyroid tumors suggest that immunocytochemical diagnosis plays a key role in assessing the malignant potential of the tumor in the preoperative stage.

Benign thyroid disease (category II BSRTC) is likely to be associated with younger patients ( $46.6 \pm 3.7$ years), low serum REA (less than $0.95 \mathrm{ng} / \mathrm{ml}$ ), poor thyroglobulin expression (77.8 \%), negative reaction with TTF-1 (100\%) and cytokeratin-19 (55.6\%).

Differential-prognostic markers of thyroid cancer with risk of malignancy ( $\mathrm{V}$ category BSRTC) include elevated serum REA (0.95 $\mathrm{ng} / \mathrm{ml}$ and above), the presence of a moderate reaction with antibodies to thyroglobulin (80.0\%), a positive reaction - to TTF-1 (100.0\%) and E-cadherin $(90.0 \%)$, with moderate or strong expression of cytokeratin-19 (90.0\%).

Statistically significant markers of malignant thyroid disease (category VI BSRTC) are: the presence of harmful factors at work (45.5\%), smoking (27.3\%), elevated serum REA $(0.95 \mathrm{ng} / \mathrm{ml}$ and above), the presence of severe cytoplasmic expression of thyroglobulin (63.6\%), moderate or severe expression of TTF-1 (90.9\%) and cytokeratin-19 (81.8\%).

Thus, the most appropriate and practically significant for preoperative diagnosis of thyroid tumors is a set of several diagnostic methods, which are carried out in one hospital - ultrasound with fine-needle aspiration, cytomorphological, and immunocytochemical and REA levels in a primary screening.

\section{REFERENCES}

1. Kravchenko V. Iodine deficiency as a cause of high prevalence of thyroid pathology in the population of regions affected by the Chernobyl accident. Journal of the National Academy of Medical Sciences of Ukraine. 2016; 22:.222-229.

2. Tronko M., Brenner A., Bogdanova T. Thyroid neoplasia risk is increased nearly 30 years after the Chernobyl accident. Int J Cancer. 2017;141: $1585-1588$.

3. Palamar B.I., Gruzieva T.S. The estimation of economic effectiveness of preventive measures of non-infectious diseases. Wiad. Lek. 2019; 72 (8): 1532-1541.

4. Shibata Y., Fuzik M., Prysyazhnyuk A. Age and gender patterns of thyroid cancer incidence in Ukraine depending on thyroid radiation doses from radioactive iodine exposure after the Chernobyl NPP accident. Problem Radiac Med Radiobiology. 2013; 18: 144-55.

5. Taylor P.N., Albrecht D., Scholz A., et al. Okosieme OE. Global epidemiology of hyperthyroidism and hypothyroidism. Nat Rev Endocrinol. 2018 May; 14(5): 301-316. doi: 10.1038/nrendo.2018.18. Epub 2018 Mar 23. PMID: 29569622. 
6. Kaminskyi, 0., Kopylova, 0., Afanasyev, D. et al. Non-cancer thyroid and other endocrine disease in children and adults exposed to ionizing radiation after the Chernobyl NPP accident. Problems of radiation medicine and radiobiology. 2015; 20: 341-55.

7. Fedorenko Z., Michailovich Y. Goulak L. Mortality from malignant neoplasms. State of oncological care to the population of Ukraine in 2017-2018. Bulletin of National Cancer Registry of Ukraine. 2019; 20:6.

8. ParkY.J., Kim J.A., Son E.J., et al. Thyroid nodules with macrocalcification: sonographic findings predictive of malignancy. Yonsei Med J. 2014 Mar; 55(2):339-44. doi: 10.3349/ymj.2014.55.2.339. PMID: 24532501; PMCID: PMC3936639.

9. Perros P., Boelaert K., Colley S. et al. Guidelines for the management of thyroid cancer. Clinical endocrinology. 2014; 81 (1): 1-122. https:// doi.org/10.1111/cen.12515--

10. Tronko M., Bogdanova T., Saenko V. Thyroid cancer in Ukraine after Chernobyl. [Nagasaki]: Nagasaki Association for Hibakusha's Medical Care. 2014.

11. Haugen B. R., Alexander E. K., Bible K. C., et al. 2015 American Thyroid Association Management Guidelines for Adult Patients with Thyroid Nodules and Differentiated Thyroid Cancer: The American Thyroid Association Guidelines Task Force on Thyroid Nodules and Differentiated Thyroid Cancer. Thyroid: official journal of the American Thyroid Association. 2016; 26(1): 1-133. https://doi.org/10.1089/ thy.2015.0020.
The work was performed in accordance with the planned scientific topics of the Department of Clinical Laboratory Diagnostics of Kharkiv National Medical University "Study of laboratory criteria of pathological, compensatory, adaptive reactions and processes in the human body to optimize diagnostic algorithms". The study has no external funding.

\section{ORCID and contributionship:}

Olga I. Zalyubovska: 0000-0003-2165-6386 ${ }^{\mathrm{E}, F}$

Nadiia O. Hladkykh: 0000-0003-3966-7462 A, B, C, D

Petro O. Gritsenko: 0000-0002-9965-8608 ${ }^{\mathrm{E}}$

\section{Conflict of interest:}

The Authors declare no conflict of interest

\section{CORRESPONDING AUTHOR Nadiia 0. Hladkykh \\ Kharkiv National Medical University \\ 4 Nauky Avenue, 61022, Kharkiv, Ukraine \\ tel: +380982683254 \\ e-mail: nadejda2692@gmail.com}

Received: 11.03 .2020

Accepted: 04.11 .2020

A - Work concept and design, B - Data collection and analysis, C - Responsibility for statistical analysis, D-Writing the article, $\mathbf{E}$-Critical review, $\mathbf{F}$ - Final approval of the article 